\title{
Costs and outcomes associated with clopidogrel discontinuation in Medicare beneficiaries with acute coronary syndrome in the coverage gap
}

This article was published in the following Dove Press journal:

Drug, Healthcare and Patient Safety

6 July 2012

Number of times this article has been viewed

\author{
Robert Lee Page II ${ }^{1,2}$ \\ Vahram Ghushchyan' \\ Richard R Allen ${ }^{3}$ \\ Lisa Roper ${ }^{4}$ \\ Don Beck ${ }^{4}$ \\ Bamrom $\mathrm{H}$ Jonathan ${ }^{4}$ \\ Feride Frech-Tamas ${ }^{5}$ \\ Wing Chan ${ }^{5}$ \\ R Brett McQueen' \\ Kavita V Nair ${ }^{\prime}$ \\ 'School of Pharmacy, Department \\ of Clinical Pharmacy, ${ }^{2}$ School of \\ Medicine, Department of Physical \\ Medicine, University of Colorado \\ Anschutz Medical Campus, \\ Aurora, CO, ${ }^{3}$ Peakstat Statistical \\ Services, Evergreen, $\mathrm{CO},{ }^{4}$ Universal \\ American, Houston, TX, ${ }^{5}$ Novartis \\ Pharmaceuticals, East Hanover, \\ New Jersey, USA
}

Background: Current guidelines for acute coronary syndrome recommend clopidogrel for an optimal period of 12 months in order to reduce the risk of reinfarction and mortality. Premature clopidogrel discontinuation has been associated with higher rates of rehospitalization, coronary stent thrombosis, and mortality. No data exist regarding the effect of the Medicare Part D coverage gap on medical costs and outcomes in Medicare beneficiaries who discontinue their clopidogrel upon entering the coverage gap.

Methods: Beneficiaries with a Medicare Advantage plan in 2009 who had a diagnosis of acute coronary syndrome were taking clopidogrel $75 \mathrm{mg}$ daily, and reached the gap in the same year representing the study sample. From this cohort, those who filled at least two prescriptions for clopidogrel (continued) versus those that did not (discontinued) while in the gap were compared with regard to outcomes related to acute coronary syndrome and expenditure 30 days after the last prescription was filled and during any time while in the gap. Descriptive and multivariate analyses were used to compare these differences.

Results: A total of 1365 beneficiaries with acute coronary syndrome met the inclusion criteria, of which 705 beneficiaries entered into the coverage gap, wherein 103 (14.6\%) and 602 (85.4\%) of beneficiaries discontinued and continued clopidogrel, respectively. Compared with those who continued clopidogrel during the gap, beneficiaries who discontinued clopidogrel showed a higher trend in the number of hospitalizations related to acute coronary syndrome and emergency room visits, albeit not statistically significant. Those who discontinued clopidogrel showed a higher mean adjusted cost per member per month in hospitalizations (\$3604) related to acute coronary syndrome and outpatient visits $(\$ 1144)$ related to acute coronary syndrome and total medical costs (\$5614), albeit not statistically significant.

Conclusion: Medicare beneficiaries who face large out-of-pocket costs for clopidogrel while in the coverage gap and discontinue therapy may experience adverse events related to acute coronary syndrome.

Keywords: Medicare, acute coronary syndrome, clopidogrel, health resource utilization

\section{Introduction}

Despite advances in medical intervention and pharmacotherapy, cardiovascular disease continues to be a leading killer in the US. ${ }^{1}$ Acute coronary syndrome (ACS) is an umbrella term that includes with either unstable angina or acute myocardial infarction consisting of ST segment elevation myocardial infarction (STEMI) or non-ST segment myocardial infarction (NSTEMI). According to American Heart Association statistics, 733,000 hospital discharges in the US in 2006 were due to ACS. Approximately 80\% of these cases comprised either unstable angina or NSTEMI, and about $20 \%$ were STEMI. ${ }^{1}$ Financially, the impact of ACS is also exceedingly high, costing Americans
Correspondence: Kavita Nair, PhD University of Colorado Anschutz Medical Campus, School of Pharmacy, Mail Stop C238, I2580 E Montview Blvd,

Aurora, CO 80045, USA

Tel + I 3037242638

Fax + I 3037242627

Email kavita.nair@ucdenver 
more than $\$ 150$ billion annually. ${ }^{2}$ Nearly $20 \%$ of patients with ACS are rehospitalized within one year and approximately $60 \%$ of the costs related to ACS are due to rehospitalization. ${ }^{3}$ Approximately one third of patients with STEMI die within 24 hours of onset of ischemia compared with $15 \%$ of patients with NSTEMI who either die or experience a reinfarction within 30 days of hospitalization. ${ }^{1}$

The etiology of ACS originates from the erosion or rupture of an unstable plaque within a coronary artery, cascading to the formation of an occlusive or nonocclusive thrombus. ${ }^{4-7}$ With this in mind, the use of dual antiplatelet therapy with aspirin and a thienopyridine such as clopidogrel (Clopidogrel ${ }^{\circledR}$, Bristol-Myers Squibb/Sanofi Pharmaceuticals, Bridgewater, $\mathrm{NJ}$ ) has become the cornerstone of therapy in order to prevent further coronary artery reocclusion and death. On the basis of clinical trial data, the American College of Cardiology/ American Heart Association recommend that medically managed patients with NSTEMI, STEMI, or unstable angina receive clopidogrel therapy for at least one month (but optimally for 12 months) and those undergoing percutaneous coronary intervention with deployment of a coronary stent independent of stent type (eg, bare metal or drug-eluting) for up to 12 months of clopidogrel after discharge. ${ }^{4,6-8}$ All patients with ACS should receive aspirin at the time of hospital admission and continue therapy indefinitely. ${ }^{4,6-8}$ Premature discontinuation of clopidogrel at any point following hospital discharge by either the patient or medical provider has been associated with higher rates of rehospitalization, coronary stent thrombosis, and mortality. ${ }^{9-16}$

A major system-level barrier contributing to potential premature clopidogrel discontinuation has been financial constraints leading to inability to obtain the medication. ${ }^{17}$ Because the average age of the first ACS event is 64.5 years for men and 70.3 years for women, a large majority of these patients will rely on medication coverage through Medicare Part D. ${ }^{1}$ Beneficiaries who exceed their initial coverage limit, will enter into the coverage gap or the "doughnut hole" where they will be required to pay $100 \%$ of their total drug costs. ${ }^{18}$ The data have suggested that such a limitation on prescription benefits can disrupt drug therapy, because of high-cost prescriptions leading to poor medication adherence, with possibly adverse health outcomes and higher medical costs. ${ }^{19-26}$ To date, no study has specifically explored the impact of entering into the gap on health outcomes and costs for Medicare beneficiaries with ACS receiving clopidogrel. In this retrospective database study, we evaluated the acute effects on health resource utilization and medical costs for beneficiaries with ACS who discontinued their clopidogrel therapy compared with those who did not upon entering the coverage gap.

\section{Materials and methods Data source}

Claims data (medical, pharmacy, and enrolment claims) for this study were obtained from Universal American, a Medicare Advantage plan serving over 200,000 Medicare beneficiaries in multiple states. The plan offers many products to Medicare beneficiaries, including health maintenance organization, preferred provider organization, and fee for service products in 2009. All products offered a pharmacy benefit, Medicare Part D plans that were similar across all products with some variations in copays levels, and generic coverage in the gap. All pharmacy benefits had an annual deductible amount of $\$ 295$, followed by a fourtier plan with retail generic copays of $\$ 15$, preferred brand copays of $\$ 30$, non-preferred brand copays of $\$ 60$, and $25 \%$ coinsurance for specialty drugs. The deductible amount, prescription copays/coinsurance, and health plan costs for medications count toward the $\$ 2700$ cap. After this cap is reached, beneficiaries have entered the gap and pay $100 \%$ of their prescription costs until their out-of-pocket costs reach $\$ 4350$. After this limit, members pay the greater of either 5\% coinsurance or $\$ 2.40$ for generics and $\$ 6.00$ for brand name medications, respectively. Of the plans we examined in 2009 , approximately $40 \%$ had coverage for generic medications only in the gap.

\section{Sample selection}

The study sample consisted of patients with ACS who were taking clopidogrel in the calendar year of 2009 and entered the gap at some time in 2009 (and may have left the gap as well). Beneficiaries were included in the study if they were enrolled in a Medicare Advantage Prescription Drug plan with a pharmacy benefit, were continuously enrolled for the entire calendar year of 2009, had an International Classification of Diseases, Ninth Revision code for NSTEMI/STEMI or unstable angina (410.xx, 411.1, 411.81, and 411.89) before they entered the gap, or had at least two prescriptions for clopidogrel at any time before they entered the gap.

\section{Demographic characteristics}

Characteristics of patients who reached the gap were examined for age, gender, evidence of diabetes, heart failure, hypertension, hyperlipidemia, obesity, stroke, and a prior myocardial infarction. Total comorbidity burden was also examined by the Chronic Condition Index (CCI). ${ }^{27}$ The 
number of individuals who underwent percutaneous coronary intervention and type of coronary stent deployed were also recorded, along with the mean number of days spent in the gap.

\section{Discontinuation of clopidogrel in the gap}

Operationalization of discontinuation can be conducted in a number of ways depending on the outcomes being examined. ${ }^{28}$ Our goal was to examine whether ACS-related medical events occurred in the gap for those who filled at least one prescription for clopidogrel (categorized as those who continued clopidogrel use in the gap) versus those who did not (categorized as those who discontinued clopidogrel use in the gap). Because entering the gap does not fall on a specific "day" for beneficiaries, but is determined by when drug costs reach a certain threshold, some decision rules were made on the definition of entering into the gap and filling a prescription within the gap. We chose to define discontinuation for those beneficiaries who did not fill a prescription for clopidogrel when they reached the gap. These beneficiaries may have had some carryover days' supply from a previous prescription for clopidogrel before they entered the gap but did not fill another prescription while they were in the gap. Beneficiaries were classified as continuing to take clopidogrel in the gap if they filled at least one prescription for the medication in the gap.

\section{Utilization}

Utilization was defined as ACS-related emergency room visits, hospital admissions for ACS, and need for percutaneous coronary intervention. For each of these utilization outcomes, two measures were developed. These consisted of beneficiaries who had an ACS-related emergency room visit, hospital admission, or percutaneous coronary intervention procedure within 30 days after their last prescription for clopidogrel while they were in the gap, and those who had an ACS-related emergency room visit, hospital admission, or percutaneous coronary intervention procedure at any time after their last prescription for clopidogrel while in the gap and before the end of the calendar year. The date after an ACS-related emergency room visit, hospital admission, or percutaneous coronary intervention procedure was defined as the date of the last prescription for clopidogrel plus the associated days' supply for that prescription. The per member per month (PMPM) number of ACS-related emergency room visits, hospital admissions, and percutaneous coronary intervention procedures in the gap were also calculated for both study groups.

\section{Expenditure}

Expenditure was defined as PMPM-related expenditure in the gap for ACS-related hospitalizations and emergency room visits, hospital admissions, and total all-cause medical expenditure while in the gap. Other explanatory variables included age (as a continuous variable), gender (with males as the reference group), CCI, whether an individual had a percutaneous coronary intervention or not (as a binary variable), and number of days spent in the gap.

\section{Statistical analysis}

All outcome measures were analyzed descriptively for those patients who either continued or discontinued clopidogrel in the gap. Multivariate analysis was also used to evaluate the impact of discontinuing clopidogrel in the gap for all the outcome measures. A negative binomial regression was used to model utilization measures. A zero-adjusted negative binomial regression was used to model the less frequent measures, such as emergency room visits, while costs were modeled using generalized linear models. Both utilization measures and cost estimates were adjusted for age, CCI, clopidogrel discontinuation, female gender, percutaneous coronary intervention, and number of days in the gap. Cost data have unique statistical properties that require the use of appropriate econometric techniques. For example, cost data are strongly right-skewed and have a significant percentage of zero-cost observations in a typical aged population. To address these properties, generalized linear models with a log link were developed because this is the link function most commonly used in literature. All analysis was conducted using STATA ${ }^{\circledR}$ version 11 (College Station, TX).

\section{Results}

Using definitions based on diagnosis and clopidogrel exposure, 1365 beneficiaries with ACS met the inclusion criteria. From this cohort, 705 beneficiaries entered into the coverage gap wherein 103 beneficiaries (14.6\%) discontinued clopidogrel in the gap, while the remaining 602 (85.4\%) continued to have a prescription for clopidogrel in the gap.

Table 1 summarizes the demographic and clinical characteristics of the beneficiaries evaluated. For patients who discontinued and continued clopidogrel, the mean age was 70 years, with $57 \%$ of beneficiaries being male. In both groups, the majority of comorbidities which were risk factors for ACS consisted of diabetes (96\%-98\%), hypertension (96\%-98\%), hyperlipidemia (92\%-95\%), and previous myocardial infarction $(51 \%-52 \%)$, with a mean CCI of 6.0 . Less than $10 \%$ of patients in either group underwent percutaneous coronary 
Table I Demographics for Medicare beneficiaries who continued or discontinued clopidogrel in the gap

\begin{tabular}{|c|c|c|c|}
\hline & $\begin{array}{l}\text { Discontinued clopidogrel in the gap } \\
(n=103)\end{array}$ & $\begin{array}{l}\text { Continued clopidogrel in the gap } \\
(n=602)\end{array}$ & $P$ value \\
\hline Age, years, mean \pm SD & $70.47 \pm 8.59$ & $70.13 \pm 8.18$ & $0.140 \mid$ \\
\hline Male (\%) & 59 (57.3\%) & $342(56.8 \%)$ & 0.9289 \\
\hline \multicolumn{4}{|l|}{ Comorbidities (\%) } \\
\hline Diabetes & 101 (98.1\%) & $578(96.0 \%)$ & 0.4067 \\
\hline Heart failure & $47(45.6 \%)$ & $238(39.5 \%)$ & 0.2440 \\
\hline Hypertension & 101 (98.1\%) & $583(96.8 \%)$ & 0.7548 \\
\hline Hyperlipidemia & $98(95.2 \%)$ & $554(92.0 \%)$ & 0.2673 \\
\hline Obesity & $16(15.5 \%)$ & $82(13.6 \%)$ & 0.6041 \\
\hline Prior MI & $54(52.4 \%)$ & $308(51.2 \%)$ & 0.8125 \\
\hline Stroke & $10(9.7 \%)$ & $80(13.3 \%)$ & 0.3143 \\
\hline Mean $\mathrm{CCl} \pm \mathrm{SD}$ & $6.46 \pm 2.08$ & $6.04 \pm 2.13$ & 0.0688 \\
\hline \multicolumn{4}{|l|}{ Percutaneous coronary intervention } \\
\hline Placement of coronary stent (\%) & $10(9.8 \%)$ & $54(9.0 \%)$ & 0.8095 \\
\hline Drug-eluting stent & $7(70 \%)$ & $40(74 \%)$ & \\
\hline Bare-metal stent & $3(30 \%)$ & $14(26 \%)$ & \\
\hline Mean time in gap $\pm S D$ (days) & $101.74 \pm 53.99$ & $145.79 \pm 68.49$ & $<0.0001$ \\
\hline
\end{tabular}

Abbreviations: $\mathrm{CCl}$, Chronic Condition Index; MI, myocardial infarction; SD, standard deviation.

intervention, with the majority receiving drug-eluting stents. Those beneficiaries who discontinued their clopidogrel spent an average of 3.5 months in the coverage gap compared with 4.8 months for those who continued therapy $(P<0.0001)$.

Figure 1 describes the percentage of beneficiaries who had ACS-related events in the gap. More beneficiaries who discontinued clopidogrel in the gap had ACS-related hospitalizations within 30 days of discontinuation $(8.7 \%$ versus $3.0 \%)$, respectively, and at any time in the gap $(21.4 \%$ versus 4.3\%) compared with those who continued taking clopidogrel during the gap. A similar trend was seen for ACS-related emergency room visits, whereby more beneficiaries who discontinued clopidogrel in the gap had ACS-related emergency room visits within 30 days of discontinuation (13.6\% versus $2.7 \%$, respectively) and at any time in the gap $(26.2 \%$ versus $4.7 \%$ ) compared with those who continued taking clopidogrel in the gap. However, similar trends were not observed for beneficiaries undergoing percutaneous coronary intervention.

Adjusted analysis comparing the mean PMPM rates of ACS-related events showed similar trends for ACS-related hospitalizations only (Table 2). Those beneficiaries who discontinued their clopidogrel had a higher number of hospitalizations for ACS compared with those who continued

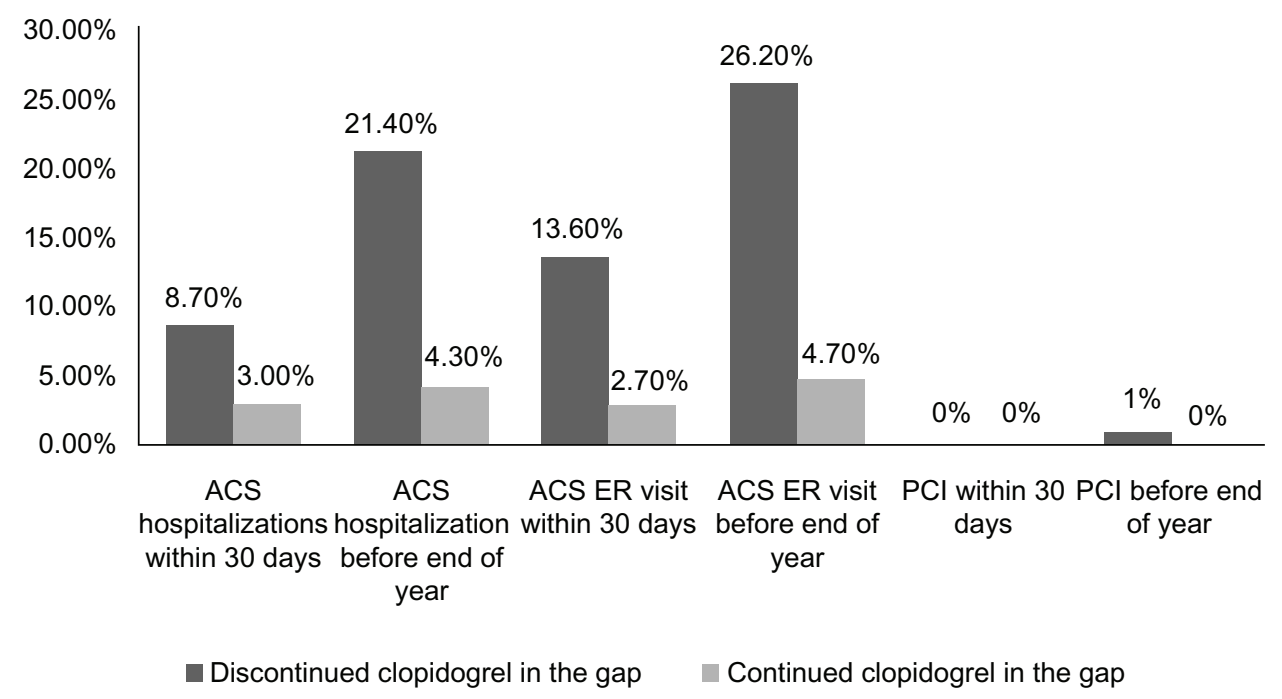

Figure I Percentage of Medicare beneficiaries with ACS-related medical utilization who continued or discontinued clopidogrel in the gap. Abbreviations: ACS, acute coronary syndromes; ER, emergency room; PCl, percutaneous coronary intervention. 
Table 2 Adjusted incidence ratios per member per month utilization for those who did or did not discontinue clopidogrel in the gap

\begin{tabular}{lll}
\hline $\begin{array}{l}\text { Outcome variable } \\
\text { (PMPM } \pm \text { SD) }\end{array}$ & $\begin{array}{l}\text { Adjusted IRR* } \\
\mathbf{( 9 5 \% ~} \mathbf{C I})\end{array}$ & $\begin{array}{l}\text { P value for } \\
\text { adjusted model }\end{array}$ \\
\hline Hospitalizations for ACS & $1.42(0.79-2.54)$ & 0.24 \\
ER visits for ACS & $1.21(0.30-4.84)$ & 0.79 \\
PCI & $0.62(0.15-2.69)$ & 0.53 \\
\hline
\end{tabular}

Notes: *Adjusted for age, Chronic Condition Index, clopidogrel discontinuation, female gender, $\mathrm{PCl}$ (stent placement), and number of days in the gap.

Abbreviations: ACS, acute coronary syndromes; $\mathrm{Cl}$, confidence interval; $\mathrm{ER}$, emergency department; IRR, incidence rate ratio; PMPM, per member per month; $\mathrm{SD}$, standard deviation; $\mathrm{PCl}$, percutaneous coronary intervention.

therapy ( $0.05 \pm 0.1$ versus $0.03 \pm 0.1$, respectively) and a higher rate of ACS hospitalization (adjusted incidence rate ratio [IRR] 1.42, 95\% confidence interval [CI] 0.79-2.54, $P=0.24)$. However, none of the differences were statistically significant.

Regarding costs, beneficiaries who discontinued clopidogrel in the gap had, on average, \$1109 higher costs for ACS-related hospitalizations compared with those who continued on clopidogrel (Figure 2). Emergency room costs showed a similar trend (\$25 PMPM versus \$9 PMPM), as did all-cause medical costs, which were $\$ 1528$ higher PMPM in the gap for those who discontinued clopidogrel compared with those who continued clopidogrel in the gap. Similar results were seen in the adjusted analysis, although the differences were not statistically significant (Table 3). Compared with those who continued their clopidogrel, beneficiaries who discontinued their clopidogrel had a trend towards higher monthly medical costs in ACS rehospitalization (adjusted mean difference \$3604), ACS physician visits (adjusted mean difference \$1144), and total medical utilization (adjusted mean difference \$5614). A minimally increased trend in emergency department visits was noted for those who discontinued therapy (adjusted mean difference \$11).

\section{Discussion}

This is the first study to evaluate the impact of the Medicare Part D coverage gap on costs and health outcomes in Medicare beneficiaries with ACS receiving clopidogrel. Each year 2.9-3.8 million Medicare beneficiaries enter into the coverage gap with no financial assistance to pay for drugs. ${ }^{19}$ During the study period of 2009, the majority of Medicare drug plans ( $75 \%$ of stand-alone plans and $49 \%$ of Medicare Advantage plans) did not offer gap coverage during the initial coverage and the catastrophic limits. ${ }^{29}$ The impact of this inability to obtain medications, particularly for chronic conditions, has been shown to have a dramatic impact on medication adherence. In a recent analysis of 217,131 Medicare beneficiaries who entered into the coverage gap, Polinski et al found that beneficiaries who received no financial assistance were $18 \%$ more likely to reduce their drug adherence. ${ }^{19}$ Among those on cardiovascular medications, there was a 2.6-fold increased likelihood of discontinuing a branded drug compared with a 1.8-fold increased likelihood of stopping a generic medication. ${ }^{19}$ Zhang et al also found a $14 \%$ reduction in drug utilization among beneficiaries with no financial assistance during the coverage gap. ${ }^{23}$ Unfortunately, limited data exist regarding the adverse health outcomes

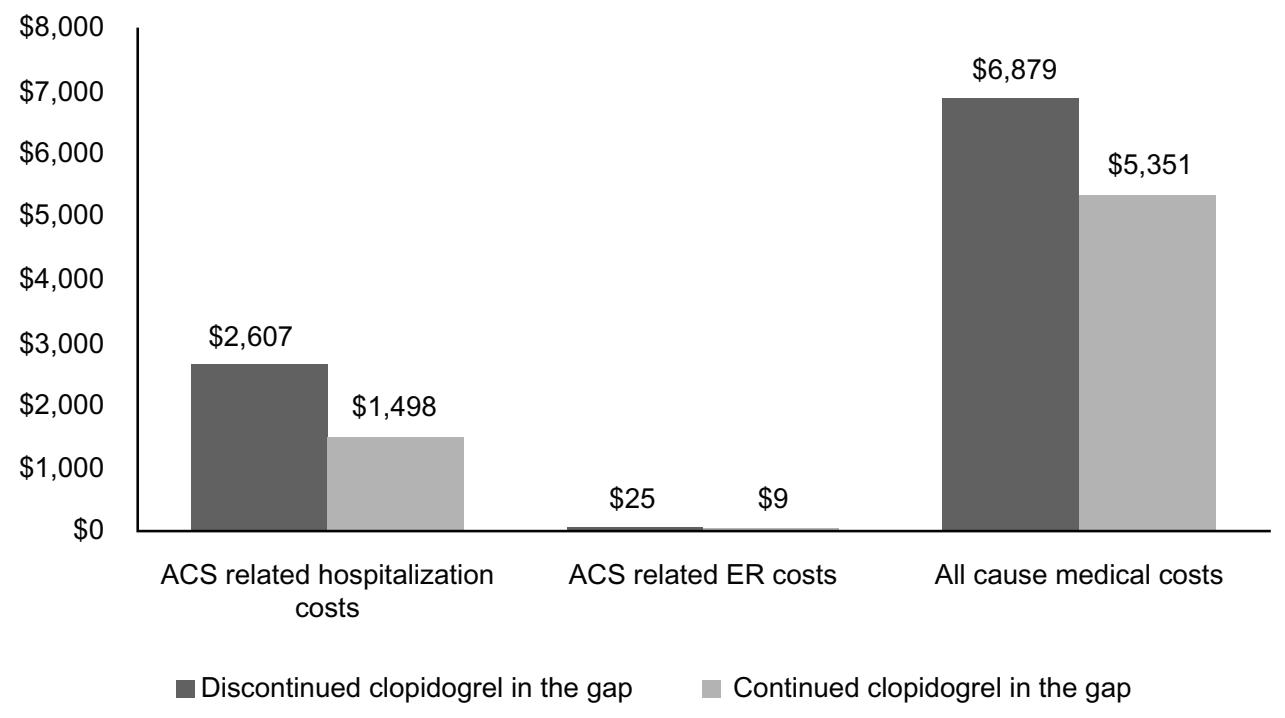

Figure 2 Per member per month expenditure for ACS-related medical utilization in Medicare beneficiaries who continued or discontinued clopidogrel in the gap. Abbreviations: ACS, acute coronary syndromes; ER, emergency room; PMPM, per member per month. 
Table 3 Adjusted mean costs per member per month for patients who did or did not discontinue clopidogrel while in the gap

\begin{tabular}{lll}
\hline $\begin{array}{l}\text { Outcome variable } \\
\text { (cost PMPM } \pm \text { SD) }\end{array}$ & $\begin{array}{l}\text { Adjusted mean } \\
\text { difference* }\end{array}$ & $\begin{array}{l}\text { P value for } \\
\text { adjusted model }\end{array}$ \\
\hline ACS hospitalization & $\$ 3604$ & 0.33 \\
ER visit for ACS & $\$ 11$ & 0.70 \\
ACS outpatient visit & $\$ 1144$ & 0.62 \\
Total medical costs & $\$ 5614$ & 0.47 \\
(ACS and non-ACS) & & \\
\hline
\end{tabular}

Notes: *Difference adjusted for age, Chronic Condition Index, clopidogrel discontinuation, female gender, percutaneous coronary intervention, and number of days in the gap.

Abbreviations: ACS, acute coronary syndromes; ER, emergency room; PMPM, per member per month; SD, standard deviation.

associated with the Medicare Part D coverage gap. In an evaluation of 2784 Medicare beneficiaries with one or more cardiovascular diagnoses, eg, hyperlipidemia, hypertension, atrial/ventricular fibrillation, or heart failure, Polinski et al found a trend of increased all-cause mortality (hazards ratio 1.27, 95\% CI 0.69-2.36) and rate of ACS (hazards ratio 1.41, $95 \%$ CI $0.55-3.62){ }^{25}$

The findings of Zhang et al are consistent with those of our study, in that $14 \%$ of beneficiaries discontinued their clopidogrel upon entering into the gap. Similar to the findings of Polinski et al, we observed a trend towards an increase in ACS-related hospitalizations and emergency room visits. However, our small sample size did not allow for any statistical differences between the two groups to be elucidated.

We also did not find any evidence of an increased need for revascularization, and this may be due to the low number of beneficiaries who actually received a coronary stent $(<10 \%)$. With this in mind, it is important to highlight that our data are more reflective of ACS patients who are using the drug for aggressive medical management rather than following percutaneous coronary intervention. Most studies evaluating the effect of premature clopidogrel discontinuation on adverse health outcomes have been performed in patients following percutaneous coronary intervention with coronary stent deployment. ${ }^{10,11,15}$ However, in the largest analysis of medically treated (ie, no percutaneous coronary intervention) patients with ACS, Ho et al evaluated the rate of all-cause mortality or acute myocardial infarction in 1568 veterans discharged with clopidogrel who discontinued therapy. ${ }^{12}$ The mean follow-up after stopping treatment was $196 \pm 152$ days. Death or myocardial infarction occurred in $17.1 \%(n=268)$ of patients, with $60.8 \%(n=163)$ of adverse events occurring 0-90 days, 21.3\% $(\mathrm{n}=27) 91-180$ days, and $9.7 \%$ $(n=26)$ 181-270 days after stopping therapy.
ACS and all-cause expenditure also showed a trend towards higher costs for those beneficiaries who discontinued clopidogrel compared with those who did not during their stay in the gap. Once again, adjusted differences did not confirm any statistical significance between the two groups with respect to this expenditure.

In addition, while we could not specifically evaluate mortality (mortality information is incomplete in claims data), our data also suggest that premature discontinuation due to the Medicare coverage cap not only leads to increased trends in the risks for ACS rehospitalization and emergency room visits, but also has the potential to incur higher medical costs related to hospitalization, outpatient visits, and overall total medical coverage.

Finally, the health plan did institute coverage of clopidogrel for Medicare beneficiaries reaching the gap in 2010 and subsequent years. However, small sample sizes of clopidogrel users in 2010 that were independent of the study sample in 2009 did not permit a between-year comparison of coverage versus no coverage for clopidogrel users in the gap.

Our study has several of the limitations associated with observational data. First, our findings are only reflective of a single Medicare Part D plan and primarily capture outcomes and costs for patients with ACS who are receiving clopidogrel for medical treatment, not after percutaneous coronary intervention. Second, due to the small number of beneficiaries who entered into the coverage gap, the study lacked the power needed to detect significant differences between groups. However, our trends in outcomes reflect those of larger studies that have evaluated adverse outcomes upon entering the gap as well as premature clopidogrel discontinuation. ${ }^{12,25}$ Third, we could only ascertain that patients had a minimum of two months of clopidogrel exposure prior to entering the gap but less than one year. Ho et al have shown that the risk of mortality and acute myocardial infarction is highest during the first 0-90 days of stopping clopidogrel when compared with 91-180 days (adjusted IRR 1.98, 95\% CI 1.46-2.69) in medically treated patients with ACS. ${ }^{12}$ In all patients with ACS receiving clopidogrel for either medical treatment or following percutaneous coronary intervention, Ho et al also found that the 0-90 day interval after stopping clopidogrel was associated with a higher risk of death and acute myocardial infarction (adjusted IRR 2.75, 95\% CI 1.69-4.44) compared with the 91-360-day interval. ${ }^{13}$ These data could explain why the magnitude of our point estimates is not larger, given that some patients may have been exposed to clopidogrel for longer than 90 days. Finally, our analysis compared clopidogrel use and the related ACS outcomes of 
those who continued the drug in the gap versus those who did not. We did not compare patterns of clopidogrel use in the groups before the members entered the gap, and we did not match the groups in our analysis due to the small sample sizes. Therefore, the groups may be inherently different in terms of adherence and other relevant characteristics.

\section{Conclusion}

The adverse clinical consequences of stopping or reducing adherence with essential evidenced-based medications can be both severe and costly. Our data add to the literature showing that Medicare beneficiaries who face large out-of-pocket costs for branded medications, such as clopidogrel, due to the coverage gap, may discontinue therapy, leading to increased health resource utilization and higher medical costs. While we only observed trends towards increases in both health resource utilization and outcome due to the coverage gap, our findings have broad clinical implications for policy and patient safety. While the Medicare Part D coverage gap is expected to close by 2020 due to the advent of health care reform, health systems should work closely with third party payers to institute comprehensive medication assistance programs for patients with conditions that warrant life-saving, evidenced-based pharmacotherapy in whom assessment of financial status is conducted at the time of hospital admission rather than at the time of discharge.

\section{Disclosure}

This study was supported by a grant from Novartis Pharmaceuticals. RLP has received funding in part through the Colorado Department of Health Policy and Financing. $\mathrm{KVN}$ and VG have been investigators on grants funded by Novartis Pharmaceuticals, none of which are manufacturers of clopidogrel.

\section{References}

1. Roger VL, Go AS, Lloyd-Jones DM, et al. Heart disease and stroke statistics - 2011 update: a report from the American Heart Association. Circulation. 2011;123(4):e18-e209.

2. Kolansky DM. Acute coronary syndromes: morbidity, mortality, and pharmacoeconomic burden. Am J Manag Care. 2009;15(Suppl 2): S36-S41

3. Menzin J, Wygant G, Hauch O, Jackel K, Friedman M. One-year costs of ischemic heart disease among patients with acute coronary syndromes: findings from a multi-employer claims database. Curr Med Res Opin. 2008;24(2):461-468.

4. Anderson JL, Adams CD, Antman EM, et al. 2011 ACCF/AHA focused update incorporated into the ACC/AHA 2007 guidelines for the management of patients with unstable angina/non-ST-elevation myocardial infarction: a report of the American College of Cardiology Foundation/American Heart Association task force on practice guidelines. Circulation. 2011;123(18):e426-e579.
5. Anderson JL, Adams CD, Antman EM, et al. ACC/AHA 2007 guidelines for the management of patients with unstable angina/non STelevation myocardial infarction: a report of the American College of Cardiology/American Heart Association task force on practice guidelines (writing committee to revise the 2002 guidelines for the management of patients with unstable angina/non ST-elevation myocardial infarction): developed in collaboration with the American College of Emergency Physicians, the Society for Cardiovascular Angiography and Interventions, and the Society of Thoracic Surgeons: endorsed by the American Association of Cardiovascular and Pulmonary Rehabilitation and the Society for Academic Emergency Medicine. Circulation. 2007;116(7):e148-e304.

6. Antman EM, Hand M, Armstrong PW, et al. 2007 focused update of the ACC/AHA 2004 guidelines for the management of patients with ST-elevation myocardial infarction: a report of the American College of Cardiology/American Heart Association task force on practice guidelines. J Am Coll Cardiol. 2008;51(2):210-247.

7. Kushner FG, Hand M, Smith SC Jr, et al. 2009 focused updates: ACC/ AHA guidelines for the management of patients with ST-elevation myocardial infarction (updating the 2004 guideline and 2007 focused update) and ACC/AHA/SCAI guidelines on percutaneous coronary intervention (updating the 2005 guideline and 2007 focused update): a report of the American College of Cardiology Foundation/American Heart Association Task Force on Practice Guidelines. J Am Coll Cardiol. 2009;54(23):2205-2241.

8. Levine GN, Bates ER, Blankenship JC, et al. 2011 ACCF/AHA/scai guideline for percutaneous coronary intervention. A report of the American College of Cardiology Foundation/American Heart Association task force on practice guidelines and the Society for Cardiovascular Angiography and Interventions. J Am Coll Cardiol. 2011;58(24):e44-e122.

9. Boggon R, van Staa TP, Timmis A, et al. Clopidogrel discontinuation after acute coronary syndromes: frequency, predictors and associations with death and myocardial infarction - a hospital registry-primary care linked cohort (MINAP-GPRD). Eur Heart J. 2011;32(19):2376-2386.

10. Ernst FR, Johnston S, Curkendall S, et al. Effect of early clopidogrel discontinuation on rehospitalization in acute coronary syndrome: results from two distinct patient populations. Am J Health Syst Pharm. 2011;68(11):1015-1024.

11. Gaglia MA Jr, Waksman R. Systematic review of thienopyridine discontinuation and its impact upon clinical outcomes. Eur Heart J. 2011;32(19):2358-2364.

12. Ho PM, Peterson ED, Wang L, et al. Incidence of death and acute myocardial infarction associated with stopping clopidogrel after acute coronary syndrome. JAMA. 2008;299(5):532-539.

13. Ho PM, Tsai TT, Wang TY, et al. Adverse events after stopping clopidogrel in post-acute coronary syndrome patients: insights from a large integrated healthcare delivery system. Circ Cardiovasc Qual Outcomes. 2010;3(3):303-308.

14. Spertus JA, Kettelkamp R, Vance C, et al. Prevalence, predictors, and outcomes of premature discontinuation of thienopyridine therapy after drug-eluting stent placement: results from the PREMIER registry. Circulation. 2006;113(24):2803-2809.

15. Wiederkehr D, Berenson K, Casciano R, et al. Clinical impact of early clopidogrel discontinuation following acute myocardial infarction hospitalization or stent implantation: analysis in a single integrated health network. Curr Med Res Opin. 2009;25(9):2317-2325.

16. Grines CL, Bonow RO, Casey DE Jr, et al. Prevention of premature discontinuation of dual antiplatelet therapy in patients with coronary artery stents: a science advisory from the American Heart Association, American College of Cardiology, Society for Cardiovascular Angiography and Interventions, American College of Surgeons, and American Dental Association, with representation from the American College of Physicians. J Am Coll Cardiol. 2007;49(6):734-739.

17. Pallares MJ, Powers ER, Zwerner PL, et al. Barriers to clopidogrel adherence following placement of drug-eluting stents. Ann Pharmacother. 2009;43(2):259-267. 
18. The Henry K. Kaiser Family Foundation. Medicare Part D 2011: the coverage gap. Available at: http://www.kff.org/medicare/upload/8222. pdf. Accessed June 5, 2012.

19. Polinski JM, Shrank WH, Huskamp HA, et al. Changes in drug utilization during a gap in insurance coverage: an examination of the Medicare Part D coverage gap. PLoS Med. 2011;8(8):e1001075.

20. The RAND Corporation. A look inside the "doughnut hole". How drug-benefit limits affect retiree prescription use. Available at: http:// www.rand.org/content/dam/rand/pubs/research_briefs/2007/RAND_ RB9285.pdf. Accessed June 5, 2012.

21. Gu Q, Zeng F, Patel BV, Tripoli LC. Part D coverage gap and adherence to diabetes medications. Am J Manag Care. 2010;16(12):911-918.

22. Zhang Y, Donohue JM, Lave JR, et al. The effect of Medicare Part D on drug and medical spending. N Engl J Med. 2009;361(1):52-61.

23. Zhang Y, Donohue JM, Newhouse JP, Lave JR. The effects of the coverage gap on drug spending: a closer look at Medicare Part D. Health Aff (Millwood). 2009;28(2):w317-w325.

24. Hales JW, George S. How the doughnut hole affects prescription fulfillment decisions involving cardiovascular medications for Medicare Part D enrollees. Manag Care. 2010;19(12):36-44.
25. Polinski JM, Shrank WH, Glynn RJ, et al. Adverse health outcomes associated with the Medicare Part D coverage gap. Abstract presented at the 27th International Society for Pharmacoepidemiology, August 13-17, 2011, Chicago, IL.

26. The Henry K Kaiser Family Foundation. The Medicare Part D coverage gap: costs and consequences in 2007. Available at: http://www.kff.org/ medicare/upload/7811.pdf. Accessed June 5, 2012.

27. The Healthcare Costs and Utilization Project. Chronic condition indicator (CCI) for ICD-9-CM. Available at: http://www.hcup-us.ahrq. gov/toolssoftware/chronic/chronic.jsp. Accessed June 5, 2012.

28. Nair KV, Frech-Tamas F, Jan S, et al. Comparing pre-gap and gap behaviors for Medicare beneficiaries in a Medicare managed care plan. $J$ Health Care Finance. 2011;38(2):38-53.

29. Neuman P, Cubanski J. Medicare Part D update - lessons learned and unfinished business. N Engl J Med. 2009;361(4):406-414.

\section{Publish your work in this journal}

Drug, Healthcare and Patient Safety is an international, peer-reviewed open-access journal exploring patient safety issues in the healthcare continuum from diagnostic and screening interventions through to treatment, drug therapy and surgery. The journal is characterized by the rapid reporting of reviews, original research, clinical, epidemiological and post-marketing surveillance studies, risk management, health literacy and educational programs across all areas of healthcare delivery. The manuscript management system is completely online and includes a very quick and fair peer-review system. Visit http://www.dovepress.com/ testimonials.php to read real quotes from published authors. 